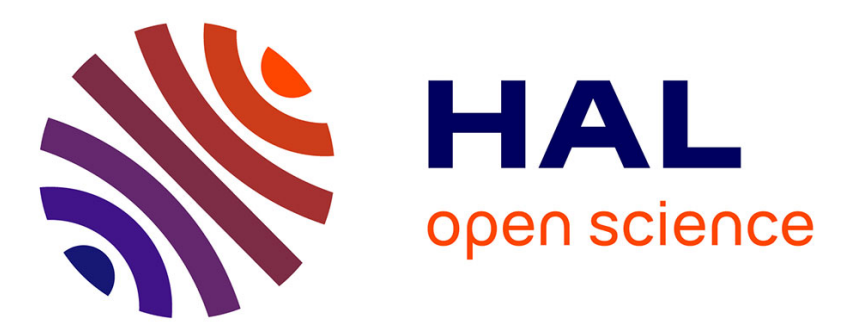

\title{
Disability in Italian Households: Income, Poverty and Labour Market Participation
}

\author{
Giuliana Parodi, Dario Sciulli
}

\section{To cite this version:}

Giuliana Parodi, Dario Sciulli. Disability in Italian Households: Income, Poverty and Labour Market Participation. Applied Economics, 2008, 40 (20), pp.2615-2630. 10.1080/00036840600970211. hal00582041

\section{HAL Id: hal-00582041 \\ https://hal.science/hal-00582041}

Submitted on 1 Apr 2011

HAL is a multi-disciplinary open access archive for the deposit and dissemination of scientific research documents, whether they are published or not. The documents may come from teaching and research institutions in France or abroad, or from public or private research centers.
L'archive ouverte pluridisciplinaire HAL, est destinée au dépôt et à la diffusion de documents scientifiques de niveau recherche, publiés ou non, émanant des établissements d'enseignement et de recherche français ou étrangers, des laboratoires publics ou privés. 


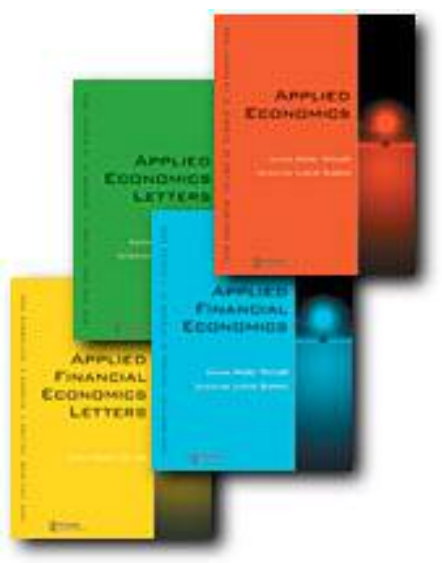

Disability in Italian Households: Income, Poverty and Labour Market Participation

\begin{tabular}{|c|l|}
\hline Journal: & Applied Economics \\
\hline Manuscript ID: & APE-06-0008.R1 \\
\hline Journal Selection: & Applied Economics \\
\hline JEL Code: & $\begin{array}{l}\text { D31 - Personal Income, Wealth, and Their Distributions < D3 - } \\
\text { Distribution < D - Microeconomics, I32 - Measurement and Analysis } \\
\text { of Poverty < I3 - Welfare and Poverty < I - Health, Education, and } \\
\text { Welfare, J22 - Time Allocation and Labor Supply < J2 - Time } \\
<\text { J - Labor and Demographic Economics, C25 - Discrete Regression } \\
\text { and Qualitative Choice Models < C2 - Econometric Methods: Single } \\
\text { Equation Models < C - Mathematical and Quantitative Methods }\end{array}$ \\
\hline Keywords: & $\begin{array}{l}\text { disability, poverty, inequality, labour market participation, } \\
\text { qualitative response models }\end{array}$ \\
\hline
\end{tabular}




\title{
DISABILITY IN ITALIAN HOUSEHOLDS:
}

\section{INCOME, POVERTY AND LABOUR MARKET PARTICIPATION}

\author{
Giuliana Parodi \\ Dipartimento di Metodi Quantitativi e Teoria Economica, Università “G. D'Annunzio". \\ Address: Viale Pindaro n. 42, 65127 Pescara, ITALY. E-mail: parodi@unich.it.
}

\section{Dario Sciulli}

PhD student in Economic Theory and Institution, University of Rome "Tor Vergata". Address: Via Columbia n. 2, 00133 Rome, ITALY.E-mail: dario.sciulli@uniroma2.it.

This paper studies the economic effects of disabled members on Italian households, with the aim of identifying a suitable target group for welfare policies. SHIW data for the year 2000 is used. Preliminary results show significant differences in levels of income and poverty diffusion to the detriment of households with disabled members. We propose an exogenous explanation: the replacement ratio between disability benefits and expected labour income shows that disability benefits do not compensate the potential incomes of the disabled person and of the possible carer, except in households with severe socio economic disadvantages. We also propose an endogenous explanation: applying a logit model we show that the labour market participation of the possible carer is reduced in households with disabled persons. In order to increase the income of the households with disabled members, policy recommendations include the provision of care services and structural policies to improve employment, income, and educational opportunities for households at greatest disadvantage.

Keywords: Disability, inequality, poverty, labour market participation, qualitative response models.

JEL codes: C25, D31, I32, J22.

\section{Author for correspondence:}

Giuliana Parodi, Dipartimento di Metodi Quantitativi e Teoria Economica, Università "G. D’Annunzio".

Address: Viale Pindaro n. 42, 65127 Pescara, ITALY.

E-mail: parodi@unich.it. 


\section{DISABILITY IN ITALIAN HOUSEHOLDS: INCOME, POVERTY AND LABOUR MARKET PARTICIPATION}

\section{INTRODUCTION}

Successful redistributive policies, whether they operate through transfer systems or through provision and pricing of welfare services, rely on information about which particular groups are the most appropriate targets. In Italy recent studies on inequality and poverty have concentrated on households with minors and households with pensioners, and demonstrated that both groups of households are at particular risk of poverty (e.g. Cannari and Franco, 1997; Baldini and Mazzaferro, 2001). We are not aware of any study concentrating on the economic situations of households with at least one disabled member, even though these households share with the previous ones the need for a high provision of caring services, and a possibly reduced earning ability of household members. In addition, the economic situation of households with disabled members could be particularly serious, on two grounds: child care has a predictable time horizon, so that, according to the characteristics of the labour market, the carer is free to participate in the labour market when the child reaches school age, while in the case of disability caring services are likely to carry on indefinitely; in addition, children are by their nature expected to be a source of expenditure, and not of income, while disability can also affect people of working age, and therefore the foregone income of disabled household members depicts circumstances which are per se unusual. The central idea of this paper is that the presence of a disabled member may affect the economic situation of the household in two ways: first in terms of increased needs, and second in terms of foregone income, both of the disabled, and of other household members affected by the situation. In order to assess the adequacy of disability benefits 
it is therefore essential to consider that the presence of a seriously disabled member requires caring services which, if provided by another member of the household, deprive the household itself of two incomes, i.e. that of the disabled member, and that of the carer. The data set is taken from the Bank of Italy's investigation into "Survey of Households Income and Wealth" in 2000 (henceforth SHIW).

The paper unfolds in two steps: first we investigate the financial situation of households with (HHD) and without (HHND) disabled members, and we find that on average HHD tend to have a lower income, and to be poorer, than HHND. Subsequently we provide two explanations for this: one in terms of replacement ratios with respect to disability benefits, and another in terms of the probability that the household member most likely to provide caring services to the disabled member (henceforth the "carer") participates in the labour market; we assume that the partner of the household head, either male or female, is the most likely to fulfil this task, and from now on we refer to this figure as the partner.

Estimates of replacement ratios show that disability benefits are lower than expected incomes in most cases, and equal to or even larger than expected incomes in cases with relative social disadvantages; also, our logit estimates show that the presence of individuals needing care, i.e. disabled members and children, negatively affects the labour market participation of the partner, pointing towards a source of further reduction in potential household incomes. Therefore our results suggest that the presence of a disabled member negatively affects the economic condition of the household, when compared with households without disabled members, except in extreme situations where all households (both with and without a disabled member) are levelled toward the bottom of the socio-economic scale. For these extreme situations the income prospects of all the members of the household are very low, and therefore fully compensated by disability benefits. According to our results two main 
mechanisms explain the relative financial disadvantage of HHD. From an exogenous point of view, disability benefits are a useful instrument for supporting the income of households with disabled members, but offer modest, and in many instances insufficient, support to compensate for the foregone income of the disabled person. From an endogenous point of view, the presence of a disabled member is likely to reduce the labour market participation of at least another household member, provoking a further loss in the potential income of the household.

The remainder of the paper is organized as follows. In section 2 we discuss methodology, data, and possible sources of bias; in section 3 we offer comparisons in terms of income, and of indicators of poverty, between HHD and HHND, in the actual scenario, and in the counterfactual scenario where disability benefits are removed; in section 4 we evaluate replacement ratios; in section 5 we present an analysis of the probability that the partner of the head of the household (henceforth "partner") in a HHD participates in the labour market; in section 6 we draw some concluding remarks and policy recommendations.

\section{METHODOLOGY, DATA, AND POSSIBLE SOURCES OF BIAS}

As stated in the previous section, this paper unfolds in two steps; a preliminary analysis of the comparison of the financial situation of HHD and HHND in terms of indicators of income levels and of poverty; and a second part investigating reasons for the relative disadvantage of HHD. This second part analyses replacement ratios with respect to disability benefits, in order to assess the extent to which disability benefits compensate the household for the loss of potential income related to the disabled member; this second part also analyses the impact of disability on the household as a whole, by 
estimating the probability of participation in the labour market of family members other than the disabled member .

In this section we discuss the methodology, the data, and the possible sources and direction of bias that some of our choices involve.

\subsection{METHODOLOGY}

In the preliminary analysis we wish to test the hypothesis that HHD are at disadvantage with respect to HHND in financial terms, because they are expected to have higher expenditures, and reduced incomes, not fully compensated by disability benefits ${ }^{1}$.

We construct indicators of income and of poverty, calculating them for HHD and HHND; the mean values of the indicators for these two groups are compared through the $\mathrm{t}$ test. Incomes are compared as equivalised incomes ${ }^{2}$; the transformation from nominal to equivalised values is effected on the basis of the widely used equivalence scale of Coulter, Cowell and Jenkins $(1992)^{3}$. The comparison of poverty between

${ }^{1}$ In this paper we do not undertake an analysis of possible additional expenditures of households with disabled member(s). See section 2.3 for a discussion on this point.

${ }^{2}$ Income inequality literature still lacks a definitive equivalence scale devoted to the studies of economic conditions of households with disabled members. An attempt has been made by INPS (the Italian DSS) to construct an equivalence factor, ISE (Indicator of the Economic Situation), which attributes a particular weight to households with disabled members; however, the ISE is based on capital as well as on income, so it is not suited to our purpose of comparing incomes.

${ }^{3} Y_{e q}=Y / \sqrt{N}$ where $Y_{e q}$ is equivalised income, $Y$ is household income and $N$ is the number of household members. In a previous version of this paper, we also used the OECD equivalence scale, which attributes different weights to the household head, other adults, and children, and we obtained the same results. 
HHD and HHND is drawn in terms of the standard ${ }^{4}$ indicators of poverty, i.e. the index of diffusion ${ }^{5}$ and of intensity ${ }^{6}$ of poverty, defining the poverty line for a family of two in terms of mean equivalised income.

Estimates of the replacement ratio are calculated as the ratio between disability benefits and expected labour income. Likelihood estimators are used to obtain a mean value of disability benefits and of wages. Expected labour income is calculated multiplying the mean wage by the probability of participating in the labour market and by the probability of finding a job, i.e. the complement to unemployment rate. Replacement ratios are calculated with respect to area of residence and gender variables, in order to reduce within group heterogeneity.

Finally, the partner participation equation is estimated by a logit model for crosssectional data. Explanatory variables include demographic and family characteristics (including a dummy variable identifying the presence of a disabled member in the household), labour market characteristics and income variables, in order to calculate substitution, cross-substitution and income effects. In order to impute earnings also to not-participant partners, and to calculate substitution effects, a Heckman selection model is used, avoiding sample selection problems in the wage prediction.

\subsection{DATA}

Our data is taken from the Bank of Italy's 2000 survey (Survey of Italian Households Income and Wealth, SHIW), which includes 22268 individuals, of which 615 (2.76\%)

\footnotetext{
${ }^{4}$ See for instance Atkinson (1970).

${ }^{5}$ Diffusion of poverty: $d=q / N$ where $q$ and $N$ are respectively the number of poor people and the total number of individuals considered.

${ }^{6}$ Intensity of poverty $I=\Sigma(y i-z) / q * z$ where $y_{i}, z$, and $q$ are respectively the income of individual $I$, the poverty line, and the number of poor people.
} 
are disabled, and 8001 households, of which $566(7.07 \%)$ have at least one disabled member.

SHIW data are widely used even though they are affected by well-known problems, such as non-answers and possible imprecision in answers ${ }^{7}$. A short description of the sub-samples used respectively in the income and in the participation analysis is provided in the sections on empirical analysis (3.1 and 5.2). It was not the purpose of the SHIW set of data to collect information on disability ${ }^{8}$; therefore the data do not allow us to quantify the degree of impairment, which could be important in analysing the effect on the household of a person's disability ${ }^{9}$. However, we believe that this set

\footnotetext{
${ }^{7}$ For a critical analysis of the limitations of SHIW data see e.g. Brandolini and Cannari (1994).

${ }^{8}$ The Bank of Italy's 2000 questionnaire, created by Ipsos-Explorer, asks in question 2 of
} frame B5 "What sort of pension do you receive?". In this paper we define as disabled those who reply to this question by crossing "disability pension" among the alternatives listed. It should be noted that the rubric "disability pension" includes both the real disability pension and the disability cheque, which are both tied to the individual's ability to work and pay tax, and also includes pensions of disability and of companionship, received for psycho-physical characteristics, whatever the work done and the contributions paid (more details to be found e.g. in Seghieri 2003, 26-40 and 540-75); this is the reason why in the article we refer to "disability benefits". The Appendix describes the sections and the questions of the questionnaire which we used, and the problems pertaining to the choice of data.

${ }^{9}$ The 1995 SHIW questionnaire does include more specific questions on the nature of the disability benefits received. European Community Household Panel (ECHP) data provide information on the individual and the family; in the section "HEALTH", question 157 deals with one's assessment of one's own state of health, and questions 158-9 refer specifically to "any chronic physical or mental health problems, illness or disability", also in relationship to how they affect daily activities. Using ECHP information would allow us to grade the level of impairment, but at the level of subjective assessment, and without distinguishing between "any 
of data is the best one in Italy for obtaining information on the disabled and on their family, rather than on the disabled only ${ }^{10}$. We have therefore to adopt the receipt of disability benefits as the pragmatic criterion for defining disability. We are aware that in so doing we are likely to come across errors of both type 1 and type 2 , i.e. excluding the bona fide disabled and including the spurious ones. However, we are reasonably confident of a small probability of committing error type 1, because in Italy a very large majority of disabled people now receive disability benefits ${ }^{11}$. In addition, it seems likely that the probability of committing error type 1, however small, applies mainly to households in situations of social disadvantage, characterized by a low social and educational level, because of their difficulties in dealing with bureaucracy (this point is further discussed in section 2.3).

The effect of adopting our pragmatic definition of disability is more serious for the probability of committing error type 2 . On this point we have two reflections about our choice: first, in Italy the overall percentage of the population with disability appears to be comparable with the $\%$ of disabled observed in other European countries. Also, for the purpose of avoiding a possible source of over-representation of the disabled, we only consider recipients of disability benefits of working age, excluding individuals

chronic physical or mental health problems, illness" and "disability". On balance we opted for using the SHIW data, which, by providing information about the recipients of disability benefits, identify disabled people officially certified as such (for a discussion of the desirability of self evaluation or objective measures of ill health see Bound (1991)).

${ }^{10}$ For a source of data on the Italian situation of the disabled, but not of their family, see the site $w w w$.disabilitaincifre.it set up by ISTAT, the Italian National Institute of Statistics.

${ }^{11}$ Since the introduction of Bill $104 / 1992$, stating the rights of the officially registered disabled, the $\%$ of registered disabled, all of whom receive at least some disability benefits, has steadily increased, reaching more or less a plateau in recent years. 
who may receive disability benefits which are in effect income support for elderly people ${ }^{12}$.

In analysing data closely tied to income (i.e. nominal income, equivalised income, indexes of inequality and poverty), we refer exclusively to households in which no household member is self-employed ${ }^{13}$; this restriction is necessary because information on income provided by self-employed workers is notoriously unreliable. By contrast, our econometric labour market participation analysis includes self-employed partners, for three reasons: first, this allows us to include the participation in the labour market of household members with flexible and non-formal income-earning activities. Second, statements about participation are not affected by the income unreliability of the selfemployed; third, in the econometric analysis we include predicted rather than declared incomes of self-employed workers, hence less affected by possible under reporting.

\subsection{POSSIBLE SOURCES OF BIAS}

In what follows we list the main sources of possible bias, grouping them by our choice of the sample, by the calculation of replacement ratios, and by participation analysis.

If, as suggested above, the probability of committing error type 1 is higher for households at social disadvantage, then particularly low incomes characterize the excluded households with disabled members, and this leads us to underestimate income and poverty diffusion gaps.

\footnotetext{
${ }^{12}$ In Italy the practice of assigning disability benefits as a form of income support to elderly people who have no other pension is not uncommon. See section 3 for a further discussion of the reasons for using this criterion for choosing our sample.

13 Therefore we include only households whose members belong to one or more of the following categories: employees, pensioners, the unemployed, and persons not belonging to the labour market.
} 
Our criterion for identifying disability also has implications for the estimate of the partner's probability of participation, in different ways according to whether error type 1 or 2 is committed; in the case of error type 1 some HHD partners (characterized by a lower participation rate) are classified as HHND partners, involving therefore an underestimation of the participation rate of HHND partners; the reverse is true in the case of error type 2. In addition, the estimation of the participation rate of HHD partners is likely to be biased by the lack of knowledge of the level of disability; in particular, it is overestimated if the disabled person suffers from a minor disability not requiring a particularly high level of care.

The value of replacement ratios is biased upwards, as it is calculated on the basis of disability benefits, which are not taxable, and incomes, which in the SHIW data are net of taxes. Our conclusions about the (low) level of replacement ratios would be even stronger if replacement ratios were calculated on the basis of gross incomes.

In this paper we do not take into account possible additional expenditures of households with at least one disabled member. The analysis would involve a careful investigation of how much of the possible additional expenditures are covered, perhaps in kind, by public provision. Should the analysis reveal, as we suspect, higher net expenditures in HHD than in HHND, our results would underestimate the relative financial disadvantages of HHD with respect to HHND.

By only considering households with household heads of working age, we lose the observations where household partners are of working age even though household heads are not, and this may affect the results in the probability of participation analysis. However, the number of such observations is small, and these are likely to be equally distributed between HHD and HHND, so no significant bias is likely to arise out of this sample selection criterion. 


\section{INCOME INEQUALITY AND POVERTY}

In this section we investigate whether the presence of a disabled member has an impact on the financial situation of the household; for this purpose we compare the financial situation of HHD and HHND with respect to incomes and poverty, in the actual scenario, and in the counterfactual scenario where disability benefits have been removed. Our analysis concerns a group of 4108 households (descriptive statistics are reported in table 1), out of which 210 have at least one disabled member; households are grouped according to idiosyncratic characteristics of the household head ${ }^{14}$.

\subsection{ACTUAL SCENARIO}

First, we test the significance of the difference in mean equivalised incomes between HHD and HHND, nation-wide, and by area of residence, comparing households by gender and by educational level of the household head. Results are reported in table 2.

For aggregate, nationwide data, and also for the Centre-North, a comparatively prosperous area in the country, HHD's incomes are significantly lower than HHND's, and this is equally true across the whole sample, both by disaggregating households by household head gender and by considering those with high levels of education; however, in the South, an area characterized by low wages and high unemployment,

${ }^{14}$ The analysis in terms of income and indicators of poverty, for reasons anticipated before, only considers households with heads below sixty five. In fact $52 \%$ of disabled are aged at least 65 , compared with $16 \%$ of non disabled; a more detailed break down of the sample in elderly people and disabled, needed to avoid the risk of confusing the income situation of disabled with that of elderly people, would make the sample too small. 
differences in incomes between HHD and HHND are never significant; interestingly, the same results are found when household heads have low education, even though they live in prosperous areas. Both situations, living in the South, and being poorly educated, correspond to high relative disadvantage, characterized by low wages and high unemployment rates; in these situations of socio economic disadvantage, disability benefits bring the HHD mean equivalised income up to the level of the HHND's. We show in section 4 , where we investigate replacement ratios with respect to disability benefits, that in these situations the incomes foregone by households because of disability are extremely low, so that on average disability benefits have a completely perequative effect, despite the fact that, as we show in section 5 , households with disabled members are likely to forego more than one income. For households with household heads living in the South and with low education, the observed phenomenon is even stronger, as foregone incomes are so low that disability benefits on average make HHD better off than HHND. Thus HHD are only as well off as, or better off than, HHND, in situations where average incomes are very low anyway.

Poverty is defined in this paper in quasi relative terms, in terms of poverty line ${ }^{15}$, defined as the half of mean equivalised income calculated over the group of all households without any self employed worker. As shown in table 3 the diffusion of poverty takes a value similar to the whole sample, about $15 \%$, for HHND, while it reaches $20 \%$ for $\mathrm{HHD}$, and the difference is statistically significant. The higher diffusion of poverty among HHD compared to HHND is highly significant in households with a female household head. This evidence can, at least partially, be explained in terms of potential income losses of male partners in HHD. In fact, given our assumption that care is provided by the partner and given the earning gender

\footnotetext{
${ }^{15}$ As usual in poverty analysis, the poverty line is defined for the whole sample. According to SHIW data it is 14776.32 liras, and $16.26 \%$ of the households are poor.
} 
differences, if the partner is male the income loss is potentially larger compared to the case in which the partner is female. On the other hand, other sub-groups show a larger diffusion of poverty for HHD, but differencesfrom HHND are not significant.

Between group differences in terms of household head characteristics show expected divergences. With or without disabled members, households with adverse characteristics, i.e. low educational level, female household heads, and living in the South, show a larger diffusion of poverty. In such cases wage discrimination, differences in labour market participation and in unemployment rates provide reasonable explanations. In fact, all the adverse characteristics considered correspond to a lower participation rate and wage, and a higher unemployment rate, implying a potential reduction in household income, hence a larger poverty diffusion.

As shown again by table 3 , no significant difference in the intensity of poverty between HHD and HHND is found. This is consistent with the results summarized in table 3: in situations of relative socio economic disadvantage, disability benefits are just sufficient to produce small and not significant differences in income between HHD and HHND because, as we show in sections 4 and 5, replacement ratios are high, given the very low expected values of the household incomes foregone because of disability. Besides, smaller values in the intensity index for HHD show for this household type a within group perequative effect ${ }^{16}$. In fact, a source of HHD income (disability benefits) is characterized by a smaller variance distribution compared to other income sources, implying a smaller inequality in the income distribution of poor households.

The situation is confirmed if we introduce fuzzy areas, i.e. we include the quasi poor, defined as those whose equivalised income ranges between $50 \%$ and $60 \%$ of equivalised income, which corresponds to $100 \%$ and $120 \%$ of the poverty line. In this

\footnotetext{
${ }^{16}$ This finding is also confirmed by the analysis of the whole sample, observing the Gini concentration coefficient estimates (see table 4).
} 
case the diffusion of poverty among HHD rises from $20 \%$ to $29 \%$, and among HHND rises from $15 \%$ to $24 \%$. A recurrent theme in these results is the disparity in conditions according to areas of residence. This is confirmed bythe distribution of the diffusion of poverty in the various situations. According to table 3 above, $8 \%$ of HHD are poor in the Centre-North, and $37 \%$ of HHD are poor in the South. The situation deteriorates if we include the quasi poor: in that case $12 \%$ of HHD are poor in the Centre-North, and $52 \%$ of HHD are poor in the South. Still according to table 3 above, approximately $6 \%$ of HHND are poor in the Centre-North, and this grows to $10 \%$ if we include the quasi poor, while approximately $33 \%$ of HHND are poor in the South, and this grows to $48 \%$ if we include the quasi poor. Less dramatic than the area effect, but still very substantial, is the effect of level of the level of education on poverty, which becomes more conspicuous than in table 3 once the quasi poor are included. For brevity we do not show these results.

\subsection{COUNTERFACTUALSCENARIO}

In order further to assess the role of disability benefits in reducing inequality between HHD and HHND, the comparisons of incomes and of poverty indicators among HHD and HHND has been repeated on the counterfactual assumptions that HHD are deprived of disability benefits ${ }^{17}$.

\footnotetext{
${ }^{17}$ At a theoretical level, the removal of disability benefits is treated as an income effect, with consequences for the observed choices in terms of consumption and leisure; our hypothesis of no change in behaviour in the counterfactual scenario implies the logically not excludable case in which the household working time is unaffected by the removal of disability benefits. At an operational level, our proposed methodology is widely used: for instance at point 7 of part 1 in European Commission (2003-2005), the perequative effect of social cash transfers is assessed calculating the poverty risk by just comparing the distribution of income with and without
} 
In the counterfactual analysis both the differences between HHD and HHND both in equivalised income and in the indicators of poverty turn out to be highly significant, and to the detriment of HHD, in all cases.

For brevity we report in table 5 only the differences between HHD and HHND in the indicators of poverty at national level. The interpretation of the findings is intuitive: HHD, whose income is reduced in the counterfactual analysis, are a minority in the whole group, therefore the poverty line has changed very little; HHD, with their reduced income, have largely fallen below the nearly unchanged poverty line.

These findings show the importance of disability benefits in reducing inequality between HHD and HHND, even if, as anticipated, only partially; in fact, by removing disability benefits for HHD, a large increase in the diffusion and intensity of poverty is found. In particular, the intensity of poverty highly increases because, removing a source of income characterized by small variance, the remaining sources of income display larger within group inequality.

\subsection{SECTION SUMMARY}

This section has highlighted the inadequacy of disability benefits to level the income and poverty situations of HHD compared with HHND, except in situations of high socio economic disadvantage: living in the South, poor level of education, and households with a female head. In the next two sections we provide explanations for the findings of the present section, both in terms of exogenous factors (section 4) and of endogenous factors (section 5).

\footnotetext{
social cash transfers; however, the Commission itself warns that this indicator must be taken with caution, as it assumes "all other thing equal".
} 


\section{REPLACEMENT RATIO BETWEEN SALARY AND DISABILITY BENEFITS}

Preliminary estimates in the previous section have shown heterogeneous income and poverty gaps between HHD and HHND. In order to explore the hypothesis that disability benefits compensate for HHD foregone incomes only in situations of socioeconomic disadvantage, we calculate the replacement ratio between disability benefits and salary, by area and by gender of the household head .The results are presented in table 6 .

Salary is calculated as the mean salary per employee, consistently with our choice to exclude households containing self employed members; the replacement ratio is calculated both on the mean salary, and on the expected mean salary; the latter depends on the participation rate and on the employment rate ${ }^{18}$.

However replacement ratios are calculated, it is clear that disability benefits are fundamental to support the income of households with a disabled member. But how adequate is this support?

Whether replacement ratios are calculated on the basis of the mean salary or of the expected mean salary, values in columns (f) and (g) of table 6 show that disability benefits only partially replace the relevant salary, except if the partner is a woman living in the South. In all other cases the replacement is only partial, with different degrees of coverage; it is always less than $50 \%$ if the basis of calculation is the mean salary, whatever the characteristics of the disabled, i.e. man or woman, living in the Centre-North or in the South. If calculated on the basis of the expected mean salary, the replacement ratio remains below $50 \%$ if the disabled member is a male living in the

\footnotetext{
${ }^{18}$ This is the criterion used by the European Union to define employment rates.
} 
Centre-North, and it rises to just over three quarters if the disabled member is a man living in the South; if the disabled member is a woman, the replacement ratio shows that disability benefits nearly compensate the expected mean income if she lives in the Centre-North, and even doubles it if she lives in the South.

These considerations apply if the replacement ratio only takes into account the potential earnings foregone by the disabled member. However, as we pointed out in the introduction, a key novelty of our paper is to consider the effects of disability in the full household context. Further considerations are therefore necessary in order to assess the perequative effect of disability benefits. The estimates we develop in section 5 show that in HHD the presence of a disabled member reduces the partner's probability of participation compared with HHND; therefore it is likely that the presence of a disabled member implies two foregone incomes rather than one, i.e. that of the disabled member, and that of the carer. In the light of these considerations, replacement ratios appear to be inadequate fully to compensate HHD for foregone incomes. The only exception concerns the case of a household in the South with a disabled female. Does this mean that in the South the presence of a disabled female does not affect the household income? The simple affirmative answer conceals the fact that, as we have repeatedly shown, the South is characterized by high poverty, high unemployment and low incomes, and therefore very low mean and expected mean incomes, so it is not the disability benefits which are high, but it is the incomes they replace which are very low.

This investigation into the values of replacement ratios taking into account idiosyncratic characteristics contributes to explain our findings in section 1, according to which the differences between HHD's and HHND's mean equivalised incomes are small and not significant in situations of relative socio economic disadvantage, but are significant in all other circumstances. 


\section{ANALYSIS OF THE PROBABILITY OF THE PARTNER'S PARTICIPATION IN THE LABOUR MARKET}

In this section we provide a possible explanation for inequality between HHD and HHND, testing for an endogenous reason. We continue to develop the analysis taking into account the situation of the disabled member within the context of the household, rather than of the disabled member in isolation. In particular we explore whether the presence of the disabled member affects the behaviour of other family members; in fact the carer is likely to be partially or fully prevented from participating in the labour market. On the assumption stated in section 1, that the carer is the partner, we apply a logit model to test whether the presence of a disabled member reduces the probability of the partner's labour market participation. This analysis is quite novel, as work has been done on the participation in the labour market of women with young children ${ }^{19}$, and on the participation of disabled people themselves in the labour market ${ }^{20}$, but no work has been done to estimate the effect of a disabled member on the participation in the labour market of another household member.

\subsection{THEORETICAL BACKGROUND AND ECONOMETRIC SPECIFICATION}

The theoretical model on which we base our econometric specification assumes that the decisions are taken by the household as a unit; therefore all decisions are taken simultaneously, so that all maximizing variables are interdependently determined.

\footnotetext{
${ }^{19}$ For instance, Chevalier and Viitanen (2002) find that the participation of women in the labour market is negatively affected by the presence of children under 5 .

${ }^{20}$ See for instance Madden (2004) and Gruber J. (2000). See also Orlando and Patrizi (2006).
} 
Households determine their optimal choices in terms of labour supply (participation) and consumption, maximizing a utility function, subject to time and budget constraints:

$$
\begin{aligned}
& \max U=U\left(C, L_{i}, J_{i}, Z_{h}, Z_{m}\right) \\
& \text { s.t. } \\
& T=H_{i}+L_{i} \\
& w_{i} H_{i}+V=p C \\
& L_{i}>0 \\
& H_{i} \geq 0
\end{aligned}
$$

where $U$ is the utility function of the household, $C$ is the household consumption, subscript $i=1,2$ refers to the household head (1) and to the partner (2), $L$ is leisure (including time devoted to housework and care), $J$ is a vector of personal characteristics, $Z_{h}$ is a vector of household characteristics, $Z_{m}$ is a vector of labour market characteristics, $T$ is the total time available, assumed to be the same for both individuals, $H$ is the time spent in working on the labour market, $w$ is the labour market wage, $V$ is unearned income (that includes non labour income of the household head and of the spouse, plus the incomes of other household members), and $p$ is the price of the consumption good.

The complete set of first order conditions, including the Kuhn-Tucker conditions, provides a system of simultaneous equations and solutions, that for brevity we do not present. Here we concentrate on the partner's choice: there is an interior solution, i.e. the hours worked in the labour market are positive, if the labour market wage for the partner is higher than his/her reservation wage $\left(w_{r}\right)$, i.e. $w_{2}>w_{r}$; this is also the condition for participation.

It seems reasonable to assume that the marginal utility of the partner's leisure is larger for those who provide care to a disabled household member than for those who 
do not; therefore the model allows for a larger reservation wage and a smaller participation rate for partners providing care.

In our empirical analysis first a Heckman selection model is estimated, then the resultant coefficients are used to predict a wage rate for the partners who do not work ${ }^{21}$. Otherwise, it would be implicitly stated that the expected market wage rate of the nonworkers is zero, which is likely to result in the wage variable being highly significant and the significance of other variables being reduced ${ }^{22}$. The Heckman (1979) procedure is a response to the potential effects of participation selection bias, which arises when interest centers on the relationship between $x$ and $w$ but data are available only for cases in which another variable, $s^{*}$, exceeds a certain value. The earnings equation of interest for all participants is: $w_{i}{ }^{*}=x_{i}{ }^{\prime} \beta+\varepsilon_{i}$ and the selection equation is given by: $s_{i}{ }^{*}$ $=z_{i}{ }^{\prime} \gamma+u_{i}$, where labour is supplied when $s_{i}{ }^{*}>0$; and thus $u_{i}>-z_{i}{ }^{\prime} \gamma$. The error terms are assumed to follow a bivariate normal distribution with means 0 and variances $\sigma_{\mu}=1$ and $\sigma_{\varepsilon}$, and correlation coefficient $\rho$. Therefore, in the sample selection model we estimate: $E\left[w_{i}{ }^{*} \mid x_{i}, s_{i}{ }^{*}>0\right]=x_{i}^{\prime} \beta+\rho \sigma_{\varepsilon} \lambda\left(-z^{\prime} \gamma\right)^{23}$.

Our participation analysis assumes that each partner faces a given market wage at which he/she can choose to work any number of hours $(H)$, or none (see Layard, Barton and Zabalza, 1980). As anticipated, if $w$ rises above $w_{r}$, the partner will supply some hours. Thus for $H>0$ the supply function is:

\footnotetext{
${ }^{21}$ Estimates of the Heckman selection model are presented in table 8.

${ }^{22}$ Some authors (for example Bailey, 2003) predict the market wage using the Tobit model, others using an OLS regression. The Tobit model constructs an independent variable which is usually bounded by zero and infinity, and typically coefficients so obtained are larger in absolute value than those from an OLS regression. However, both techniques can involve biased estimates whenever sample selection problems arise.

${ }^{23} \lambda\left(-z^{\prime} \gamma\right)=\phi(-w \gamma) /(1-\Phi(-w \gamma))$ is the inverse Mills ratio.
} 
$H=Q^{\prime} \beta+\varepsilon$

where $Q$ is a set of covariates. We indicate:

$\hat{H}=Q^{\prime} \beta$

which may well be negative for someone whose measured characteristics do not dispose them to work. Finally:

$$
H= \begin{cases}\hat{H}+\varepsilon & \text { if } \hat{H}+\varepsilon>0 \\ 0 & \text { if } \hat{H}+\varepsilon \leq 0\end{cases}
$$

The probability of working is:

$$
P=\operatorname{Pr}(\hat{H}+\varepsilon>0)=\operatorname{Pr}(\varepsilon>-\hat{H})=1-F(-\hat{H})
$$

where $F$ is the cumulative density function of $\varepsilon$. Every individual has a participation probability defined as follow:

$$
p_{i}= \begin{cases}1 \text { if } \quad \hat{H}+\varepsilon>0 & \text { with probability } 1-F(-\hat{H}) \\ 0 \text { if } \quad \hat{H}+\varepsilon \leq 0 & \text { with probability } F(-\hat{H})\end{cases}
$$

In particular, the participation decision is estimated by a logit model, hence $F$ is assumed to be a logistic. The logit specification is the follow: 


$$
\operatorname{Pr}\left(p_{i}=1\right)=1-F(-\hat{H})=\frac{\exp \left(q_{i}{ }^{\prime} \beta\right)}{1+\exp \left(q_{i}^{\prime} \beta\right)}
$$

\subsection{RESULTS}

The regression estimates the rates of participation in the labour market of the partners in the households sampled by SHIW, with personal, household, income, and labour market characteristics as explanatory variables. A group of 4236 individuals has been identified, made up of all the partners in working age ${ }^{24}$, including the self-employed.

Participants are defined as the employed, the strictly unemployed, and the first job seekers; everybody else has been defined as non participant. Covariates used are: partner's predicted annual labour income, household head's annual labour income, family annual unearned income, age and age square, two regional dummies (North and South, the omitted category is Centre), a continuous variable for education, a gender dummy, a set of dummy variables in order to indicate the presence of disabled persons, pre-schooled aged children, elderly people and, finally, the unemployment rate, defined in sixteen different groups related to personal characteristics (age, education, gender and region). The descriptive statistics relating to this sample are described in table 7.

The second column of table 9 shows the results of the logit analysis, the third column reports the standard errors, while the fifth column shows the marginal effect of an increase of a unit in the covariate values on participation, evaluated at the mean of the dependent variable. Finally, in table 10 we show observed and predicted participation rates, while in table 11 we show the estimates of the elasticities.

\footnotetext{
${ }^{24}$ Working age for participation analysis diverges between men and women. We fixed it at 65 years for men and 60 years for women, in accordance with Italian retirement legislation.
} 
In table 9, the estimates of the covariates' coefficients have the expected signs, except the North dummy (but the estimate is not significant). Our estimates of the age variable predict a typical inverted $U$ effect on participation, and they are significant at $5 \%$ and $1 \%$ level. One extra year of education increases the participation probability by $2,7 \%$, and the estimate is significant at $1 \%$ level. With regard to area dummies, the North dummy is not significant, while an individual living in the South has a probability of participation about $19 \%$ less than someone with the same characteristics but not living in the South. As we can expect, the relative probability of participation in the labour market for males is $41 \%$ greater than for females. The unemployment rate negatively affects the partner' participation, and points in the direction of the behavioural hypothesis of the discouraged worker. The presence of preschool-aged children negatively affects the partner's participation probability (about 9,2\%), the presence of children 6-14 years old has a negative effect (about 7,6\%) on the participation decision, while the presence of elderly members affects it positively (about 9\%). The estimates of income variables are all $1 \%$ significant and show the expected signs. Finally, the presence of disabled members, as expected, negatively affects participation, but the estimate is not significant.

As pointed out in section 1, our criterion for identifying disabled persons is likely to involve some bias in the estimation of the participation decision of the partner. However, given that the most relevant identification problem relates to type 2 errors rather than to type 1 errors, our choice criterion involves the underestimation of the effect of the presence of disabled members on the participation decision of the partner.

A further consideration seems to be necessary: we suggested in section 1 that the effect of the presence of disabled members on the partner's probability of participation is very similar to the effect of the presence of other individuals needing care, i.e. preschool aged children. In other words, this last variable can be used as a proxy in order 
to capture the effect of the presence of members needing care, including disabled members, on participation rates. Our estimates show a negative and significant effect of the children 0-5 variable, strengthening our predictions of the effect of disabled, or other care-needing members, on participation rates.

Our findings are confirmed by the predicted participation rate. Table 10 displays the observed and predicted participation rates: the predicted and the observed participation rates show a strong and significant difference between HHD and HHND (35.2\% versus $59.6 \%$ ). Hence, even if the estimate of the disabled variable is not significant, the participation rate appears to be affected by the presence of disabled members.

With regard to income variables, in table 11 we present the substitution, crosssubstitution and income effects. As anticipated, all effects are significant and show the expected signs. Our elasticity estimates confirm an indirect negative effect related to disabled members. In fact, all elasticities show smaller absolute values for HHD partners compared with HHND. These results confirm that the presence of disabled members can represent an obstacle (or a disincentive) to partners' labour market participation. In particular, the substitution effect is 0.31 for HHD partners, while it is 0.33 for HHND. With predicted increasing own earnings the participation rate increases, but the effect is less strong. At the same time, cross-substitution effects are negative but these effects are stronger for HHD than for HHND partners (-0.10 versus 0.08). We obtain the same results for the income effects (-0.12 for HHD partners versus -0.07 for HHND). In other words, HHD partners show a relatively more rigid probability of participation with respect to increases in their own earnings, while their probability of participation is more elastic with respect to increases in household head earnings and in unearned income. 


\subsection{SECTION SUMMARY}

In this section we have provided a possible theoretical explanation for HHD partners' observed lesser participation in the labour market. Our empirical tests, applying a logit model and comparing observed and predicted participation rates, seem to confirm theoretical predictions, i.e. a negative effect of the presence of disabled members on partners' participation decisions.

\section{SUMMARY AND POLICIES}

The paper has proposed a fresh approach to the study of the economics of disability, by analysing the disabled within the household context, rather than in isolation, with the methodology discussed in sections 1 and 2.

The first part of our analysis (section 3) offers original findings on the relative financial situations of households with and without disabled members; it has been shown that on average HHD have lower income than HHND, that all HHD would be severely disadvantaged if disability benefits were removed, that in general the diffusion of poverty is higher among HHD than among HHND, and that disability benefits are sufficient to close the income gap between HHD and HHND only in the lowest socio economic brackets, where mean and expected incomes are very low.

The analysis in section 4 shows that the relation between disability benefits and expected income varies widely across circumstances, i.e. areas and gender. Given that disability benefits are the same throughout the country, different values of replacement ratios depend on expected labour incomes; obviously, replacement ratios are largest in areas where expected incomes are lowest.

Section 5 investigates the impact of the disabled on the working behaviour of the household. To our knowledge such a study has not been carried out before. The logit 
model shows that a disabled member in the household reduces the likelihood that the partner participates in the labour market; we suggest that this is because the partner acts as carer, and we conclude that disability in one member is likely to lose the household two incomes, not one only.

These findings of sections 4 and 5 together explain why the incomes of HHD and HHND are quite similar in situations of greatest socio economic disadvantage, characterized by low wages, employment opportunities and education. If the replacement ratio is two, disability benefits compensate for the expected incomes of two members, i.e. the disabled member and the carer, so there is no difference between the income of households with and without disabled members. However, the smaller the replacement ratio, the less disability benefits compensate for the household's foregone incomes (of the disabled member and of the carer): if the replacement ratio is one, disability benefits make up for the income of the disabled member, but not of the carer, and this already makes HHDs' income lower than HHND; if the replacement ratio is less than one, only part of the disabled member's foregone income is compensated for, and the foregone income of the carer is not replaced at all, so that there are even more reasons for HHD incomes to be lower than HHND. To a disabled male in the Centre-North in a medium or high income household, disability benefits are not even half his expected income, while to a female disabled in the South disability benefits are over twice her expected income.

Another important finding of our research is the persistent disadvantage of households with low income potential, i.e. with household heads with low education, or living in the South, whatever the grouping criteria. In the year 2000, the mean equivalised income of both HHD and HHND living in the South was smaller than the mean equivalised income of comparable groups living in the Centre-North, while the diffusion of poverty in the South is larger than in the Centre-North. The disparity 
between areas remains large even if in calculating the diffusion of poverty we include the quasi poor. Analogous considerations with respect to differences in income and diffusion of poverty apply when we compare HHD and HHND with household heads with different levels of education; income and poverty differences become larger if we calculate the diffusion of poverty including the quasi poor.

Policy implications for the purpose of reducing income disparities between HHD and HHND are either an increase in the amount of disability benefits, or an increase in the provision of public caring services for the disabled, or a mixture of the two. The redistributive effects of these two alternative instruments are different: disability benefits are paid through general taxation, while the provision of caring services is generally the responsibility of local authorities. The amount of provision of caring services would therefore depend on how affluent the various local authorities are, while an increase in disability benefits would be homogeneous throughout the country. The usual problem of the desirability of benefits in cash rather than in kind also arises in this context.

Our results also call for deep structural policies not immediately related to disability: according to our findings in situations of social disadvantage (whether geographical, or in terms of personal characteristics) replacement ratios with respect to disability benefits are nearly one, or even higher than one. This simply highlights that replacement ratios appear to be very high when the same level of disability benefits is compared with very low expected incomes in situations of social disadvantage. These low expected incomes, particularly evident in the South, call for policies geared at increasing the opportunities of employment, and/or the level of wages, and/or the educational qualification of the labour force, or for a mixture of these all. These policies would also improve participation rates, given that the analysis developed in section 4 points in the direction of the behavioural model of the discouraged worker. 
Much remains to be done in comparing the financial situation of HHD and HHND. We suggest three directions for future research which would assist in identifying the appropriate mix of equitative policies. First, information about degrees of disability is desirable; this could perhaps be achieved by combining SHIW and INPS-ISTAT data. Second, possible special needs of HHD ought to be explicitly considered, as they may result in a vector of expenditures different from HHND, and also, in the long run, in less savings and accumulation of capital. Third, it would be desirable to quantify the total amount of public transfers in kind provided to HHD to assist with care of the disabled member. In this connection, it is highly desirable that the surveys geared at gathering information on disability collect data setting the disabled within the socioeconomic context to which they belong.

\section{ACKNOWLEDGEMENT}

We wish to thank an anonymous referee for useful comments and suggestions. 


\section{APPENDIX}

The data used in this paper was collected in 2000 by the Bank of Italy for a survey which it conducts periodically on the consumption habits of Italian households.

The following SHIW files were used: carcom, containing information about characteristics of individuals and households (age, gender, educational level, area of residence, type of employment, degree of kinship to head of household, number of breadwinners in household, etc.); allb5, from which we identified households containing at least one disabled member, and which we used to calculate the annual value of disability benefits; rfam, containing information about households' income; allb1, containing information about self-employed workers.

As specified above, all households which declared an income deriving from selfemployment were excluded from the analysis on income and on poverty, so as to maximise the reliability of results. This was possible using the information in the rfam file.

All individual characteristics of the households (gender, area of residence, educational level) are recorded about the head of the household, who is assumed to be representative.

By convention, when income was declared to be negative (which happened very rarely) we computed it as nought.

We did not include information from HHD households which did not declare the monthly value of the disability benefits (this information was important in the counterfactual exercise).

In the analysis of the probability of the partner's participation in the labour market, we abandoned some hypotheses made at the outset. In particular, the information about personal characteristics pertains directly to the partner (as opposed to the household head), and the definition of working age was differentiated for men (15 - 64) and 
women $(15-60)$. The data about unemployment by category, used as regressor, was taken from the SHIW file carcom.

For data on the average salary, which we compared with the value of disability benefits, we turned to the file allb1, from which it was possible to calculate the annual net income of workers who are not self-employed. To maximise homogeneity we only considered individuals employed throughout the year, i.e. excluding seasonal workers.

Having worked exclusively on SHIW data, we used this to calculate the degrees of participation and employment which determine the value of expected incomes for all the considered groups. 


\section{REFERENCES}

Atkinson, A. B. (1970) On the Measurement of Inequality, Journal of Economic Theory, 2, 244-263.

Bailey, M. F. (2003) The labour market participation of Northern Ireland University Students, Applied Economics, 35, 1345-1350.

Banca d'Italia (2002) I bilanci delle famiglie italiane nell'anno 2000, Supplemento al Bollettino Statistico, Note metodologiche e informazioni statistiche, Nuova serie, 12 , 11.

Baldini, M. and C. Mazzaferro (2001) "Sistema pensionistico e distribuzione dei redditi in Italia dal 1977 al 1998: un'analisi sull'archivio storico dell'indagine campionaria della Banca d'Italia", Materiali di discussione del Dipartimento di Economia Politica dell'Università di Modena e Reggio Emilia, Working Paper 351.

Bound J. (1991) Self-reported versus objective measures of health in retirement models, Journal of Human Resources, 26, 106-38.

Brandolini, A. and L. Cannari (1994) Methodological Appendix: The Bank of Italy's Survey of Household Income and Wealth, in Saving and the Accumulation of Wealth. Essays on Italian Households and Government Saving Behaviour, (Eds) A. Ando, L. Guiso and I. Visco, Cambridge University Press, Cambridge, pp. 369-386.

Brucchi, L. (2001) Manuale di Economia del Lavoro, Il Mulino, Bologna.

Cannari, L. and D. Franco (1997) La povertà tra i minorenni in Italia: dimensioni, caratteristiche e politiche, Temi di discussione, Banca d'Italia, 294.

Chevalier, A and T. K. Viitanen (2002) The causality between female labour force participation and the availability of childcare, Applied Economics Letters, 9, 915-918.

Coulter F. A. E., F. A. Cowell and S. P. Jenkins (1992) Equivalence Scale Relativities and the Extent of Inequality and Poverty, Economic Journal, 102, 1067-1082. 
European Commission (2003-2005), Joint Report on Social Inclusion summarising the results of the examination of the National Action Plans for Social Inclusion, Working Document 1425 of the Spring European Council (2003).

Greene, W. H. (2003) Econometric Analysis, 5th edn, New York University, New York.

Gruber J. (2000) "Disability Insurance Benefits And Labour Supply", Journal of Political Economy, 198, 1162-1183.

Heckman, J. J. (1979) Sample selection bias as a specification error, Econometrica, 47, 153-161.

Killingsworth, M. R. and J. J. Heckman (1986) Female labour supply: a survey, in Handbook of Labor Economics, vol. 1, (Eds) O. Ashenfelter and R. Layard, NorthHolland, Amsterdam.

Main, G. M. and B. Reilly (1994) Married women's hours and participation revisited, Applied Economics, 26, 277-281.

Layard, R., M. Barton and A. Zabalza (1980) Married women's participation and hours, Economica, New series, 47, 51-72.

Neter, J. et al. (1996) Applied Linear Regression Models, 3rd edn, Irwin, Chicago.

Orlando, N. and M. Patrizio (2006) Il collocamento mirato dei disabili: l'applicazione della legge 68/1999 nella provincia autonoma di Bolzano, in Aspetti Socio-economici della Disabilità : Atti del Convegno tenutosi a Pescara, marzo 2006 (Ed.) G. Parodi, Aracne, Rome, forthcoming.

Ribar, D. (1995) Structural model of childcare and the labour supply of married women, Journal of Labor Economics, 13, 558-597.

Seghieri, L. (2003) Diritti sociali dalla A alla Z. Enciclopedia dei diritti dei lavoratori, De Lillo, Milan. 
Table 1: Descriptive statistics of the sample for income and poverty analysis.

\begin{tabular}{lcc} 
Variable & Mean & Std. Dev. \\
\hline age & 47.33 & 10.631 \\
male & 0.69 & 0.464 \\
high education & 0.43 & 0.496 \\
low education & 0.57 & 0.496 \\
Centre-North & 0.64 & 0.481 \\
South & 0.36 & 0.481 \\
HH size & 3.07 & 1.254 \\
HH with disabled & 0.05 & 0.220 \\
monthly disability benefits & 745.83 & 456.703 \\
equivalent income & 30375.34 & 18000.900 \\
poverty & 0.1560 & 0.363 \\
intensity & 0.3793 & 0.294 \\
\hline
\end{tabular}

Source: our elaboration of SHIW (2000) data.

Table 2: Summary of the analysis of the discrepancies in equivalised mean income, approximated in liras (000), by characteristics of head of household.

\begin{tabular}{|c|c|c|c|c|c|c|}
\hline \multirow[b]{2}{*}{ Area } & \multirow[b]{2}{*}{ Head of $\mathrm{HH}$} & \multicolumn{2}{|c|}{ HHD } & \multicolumn{2}{|c|}{ HHND } & \multirow[b]{2}{*}{ t-test } \\
\hline & & Eq. mean Y & Std. err. & Eq. mean Y & Std. err. & \\
\hline \multirow{5}{*}{ Nation-wide } & All & 26792 & 935.51 & 30568 & 291.36 & $* * *$ \\
\hline & Man & 28183 & 1158.20 & 31348 & 355.87 & $* *$ \\
\hline & Woman & 23690 & 1510.90 & 28872 & 503.40 & $* *$ \\
\hline & High education & 31862 & 1678.81 & 37726 & 491.59 & $* *$ \\
\hline & Low education & 25208 & 1082.67 & 24868 & 294.90 & \\
\hline \multirow{5}{*}{ Centre-North } & All & 31193 & 1169.40 & 35564 & 363.22 & $* * *$ \\
\hline & Man & 32627 & 1437.46 & 36387 & 438.19 & $*$ \\
\hline & Woman & 27689 & 1871.78 & 33750 & 645.02 & $* *$ \\
\hline & High education & 32561 & 1929.38 & 41312 & 599.57 & $* *$ \\
\hline & Low education & 30612 & 1453.18 & 30212 & 366.76 & \\
\hline \multirow{5}{*}{ South } & All & 20447 & 1264.57 & 21683 & 387.64 & \\
\hline & Man & 21322 & 1560.64 & 22278 & 486.75 & \\
\hline & Woman & 18725 & 2160.89 & 20419 & 627.11 & \\
\hline & High education & 29871 & 3468.79 & 29509 & 739.46 & \\
\hline & Low education & 18768 & 1268.12 & 17004 & 348.95 & \\
\hline
\end{tabular}

Three, two and one starred t values are significant at $99 \%, 95 \%$ and $90 \%$ respectively.

Source: our elaboration of SHIW (2000) data. 
Table 3: Diffusion and intensity of poverty among HHD and HHND, according to characteristics of head of households.

\begin{tabular}{|c|c|c|c|c|c|c|c|c|c|c|}
\hline \multirow[b]{3}{*}{ Head of $\mathrm{HH}$} & \multicolumn{5}{|c|}{ Diffusion } & \multicolumn{5}{|c|}{ Intensity } \\
\hline & \multicolumn{2}{|c|}{ HHD } & \multicolumn{2}{|c|}{ HHND } & \multirow[b]{2}{*}{ t-test } & \multicolumn{2}{|c|}{ HHD } & \multicolumn{2}{|c|}{ HHND } & \multirow[b]{2}{*}{ t-test } \\
\hline & $\%$ & Std. err. & $\%$ & Std. err. & & $\%$ & Std. err. & $\%$ & Std. err. & \\
\hline$\overline{\text { All }}$ & $20.00 \%$ & 0.028 & $15.37 \%$ & 0.006 & $*$ & $31.34 \%$ & 0.033 & $38.39 \%$ & 0.012 & \\
\hline Man & $15.86 \%$ & 0.030 & $14.30 \%$ & 0.007 & & $31.19 \%$ & 0.041 & $36.85 \%$ & 0.015 & \\
\hline Woman & $29.23 \%$ & 0.057 & $17.69 \%$ & 0.011 & $* *$ & $31.52 \%$ & 0.055 & $41.09 \%$ & 0.021 & \\
\hline High education & $10.00 \%$ & 0.043 & $6.60 \%$ & 0.006 & & $24.25 \%$ & 0.115 & $30.06 \%$ & 0.026 & \\
\hline Low education & $23.13 \%$ & 0.033 & $22.35 \%$ & 0.009 & & $32.30 \%$ & 0.035 & $40.35 \%$ & 0.014 & \\
\hline Centre-North & $8.06 \%$ & 0.025 & $5.53 \%$ & 0.005 & & $22.54 \%$ & 0.056 & $33.36 \%$ & 0.025 & \\
\hline South & $37.21 \%$ & 0.052 & $32.86 \%$ & 0.012 & & $34.09 \%$ & 0.039 & $39.89 \%$ & 0.014 & \\
\hline
\end{tabular}

Three, two and one starred t values are significant at $99 \%, 95 \%$ and $90 \%$ respectively.

Source: our elaboration of SHIW (2000) data.

Table 4: Gini's concentration coefficient for HHD and HHND, calculated on equivalised incomes. (Bootstrap estimates).

\begin{tabular}{lcccccc} 
& \multicolumn{3}{c}{ HHD } & \multicolumn{3}{c}{ HHND } \\
\cline { 2 - 7 } Head of HH & Observed & bias & Std. err. & Observed & bias & Std. err. \\
\hline All & 0.2821 & -0.0010 & 0.0116 & 0.2996 & -0.0005 & 0.0039 \\
Man & 0.2752 & -0.0007 & 0.0136 & 0.2975 & 0.0003 & 0.0044 \\
Woman & 0.2881 & -0.0019 & 0.0198 & 0.3026 & -0.0006 & 0.0074 \\
High education & 0.2095 & -0.0058 & 0.0244 & 0.2684 & 0.0008 & 0.0056 \\
Low education & 0.2971 & -0.0022 & 0.2235 & 0.2920 & -0.0004 & 0.0048 \\
Centre-North & 0.2301 & -0.0008 & 0.0135 & 0.2548 & -0.0011 & 0.0045 \\
South & 0.3155 & -0.0047 & 0.0208 & 0.3266 & -0.0004 & 0.0062 \\
\hline
\end{tabular}

Source: our elaboration of SHIW 2000 data

Table 5: HHD and HHND indexes of the measures of poverty calculated on equivalised incomes, disability benefits removed.

\begin{tabular}{|c|c|c|c|c|c|c|c|c|c|c|}
\hline \multirow[b]{3}{*}{ Head of $\mathrm{HH}$} & \multicolumn{5}{|c|}{ Diffusion } & \multicolumn{5}{|c|}{ Intensity } \\
\hline & \multicolumn{2}{|c|}{ HHD } & \multicolumn{2}{|c|}{ HHND } & \multirow[b]{2}{*}{ t-test } & \multicolumn{2}{|c|}{ HHD } & \multicolumn{2}{|c|}{ HHND } & \multirow[b]{2}{*}{ t-test } \\
\hline & $\%$ & Std. err. & $\%$ & Std. err. & & $\%$ & Std. err. & $\%$ & Std. err. & \\
\hline$\overline{\text { All }}$ & $37.62 \%$ & 0.034 & $14.98 \%$ & 0.006 & $* * *$ & $53.64 \%$ & 0.037 & $38.21 \%$ & 0.012 & *** \\
\hline
\end{tabular}

Table 6: Replacement ratio.

\begin{tabular}{llcccc} 
& & \multicolumn{2}{c}{ Centre-North } & \multicolumn{2}{c}{ South } \\
\cline { 3 - 6 } Group & & Man & Woman & Man & Woman \\
\hline Mean wage (in 000 liras) & (a) & 29456,83 & 21177,05 & 24049,00 & 19242,27 \\
Mean disability benefits (in 000 liras) & (b) & 9163,48 & 9434,25 & 10644,76 & 8497,52 \\
Participation rate (\%) & (c) & $7229,00 \%$ & 51,79 & 74,82 & 35,92 \\
1 - unemployment rate (\%) & (d) & 94,13 & 92,72 & 75,01 & 67,97 \\
Expected mean wage (in 000 liras) & (e) $=(\mathrm{a}) *(\mathrm{c}) *(\mathrm{~d})$ & 20045,88 & 10456,71 & 13496,4 & 4697,64 \\
\hline Replacement Ratio on mean wage & $(\mathrm{f})=(\mathrm{b}) /(\mathrm{a})$ & 0,31 & 0,43 & 0,44 & 0,44 \\
Replacement Ratio on Expected mean wage & (g) $=(\mathrm{b}) /(\mathrm{e})$ & 0,46 & 0,9 & 0,79 & 1,81 \\
\hline Souryyyyy
\end{tabular}

Source: our elaboration of SHIW (2000) data. 
Table 7: Descriptive statistics for analysis of partners' participation.

\begin{tabular}{llcc} 
Variable & Description & Mean & Std. Dev. \\
\hline Age & individual age & 44,76 & 9,44 \\
Gender & individual gender & 0,20 & 0,40 \\
North & area of residence & 0,43 & 0,50 \\
Centre & area of residence & 0,20 & 0,40 \\
South & area of residence & 0,37 & 0,48 \\
High & high education level & 0,09 & 0,29 \\
Medium & medium education level & 0,32 & 0,47 \\
Low & low education level & 0,59 & 0,49 \\
Schooling & years of schooling & 9,50 & 4,12 \\
Children 0-5 & presence of children 0-5 years old & 0,19 & 0,39 \\
Children 6-14 & presence of children 6-14 years old & 0,33 & 0,47 \\
Elderly & presence of elderly & 0,08 & 0,27 \\
Disabled members & presence of disabled members & 0,03 & 0,17 \\
Unemployment rate & unemployment rate & 0,10 & 0,12 \\
\hline Unearned income & not labour income & 14748,57 & 18473,03 \\
Husband income & husband earning & 27561,66 & 23170,02 \\
Own income & predicted partners earning & 12274,35 & 8127,11 \\
\hline Source: our elaboration of SHIW (2000) data. & &
\end{tabular}

Source: our elaboration of SHIW (2000) data. 
Table 8: Heckman Model estimates.

\begin{tabular}{|c|c|c|c|c|}
\hline Covariates & Coef. & Std. Err. & $\mathrm{P}>|\mathrm{z}|$ & Sign \\
\hline \multicolumn{5}{|c|}{ Earning equation } \\
\hline age & 2856.98 & 282.12 & 0.000 & $* * *$ \\
\hline age square & -35.02 & 3.17 & 0.000 & $* * *$ \\
\hline gender & 9172.69 & 1392.94 & 0.000 & $* * *$ \\
\hline north & 2445.10 & 760.23 & 0.001 & $* * *$ \\
\hline south & -1554.91 & 962.01 & 0.106 & \\
\hline high & 8775.80 & 1013.58 & 0.000 & $* * *$ \\
\hline low & -8877.00 & 862.10 & 0.000 & $* * *$ \\
\hline constant & -39877.51 & 6361.13 & 0.000 & $* * *$ \\
\hline \multicolumn{5}{|c|}{ Selection equation } \\
\hline$\overline{\text { age }}$ & 0.032 & 0.027 & 0.243 & \\
\hline age square & 0.000 & 0.000 & 0.119 & \\
\hline gender & 2.125 & 0.095 & 0.000 & $* * *$ \\
\hline north & 0.176 & 0.060 & 0.004 & $* * *$ \\
\hline south & -0.537 & 0.071 & 0.000 & $* * *$ \\
\hline high & 0.753 & 0.105 & 0.000 & $* * *$ \\
\hline low & -0.705 & 0.053 & 0.000 & $* * *$ \\
\hline children $0-5$ & -0.149 & 0.071 & 0.035 & $* *$ \\
\hline children 6-14 & -0.037 & 0.055 & 0.505 & \\
\hline elderly & 0.155 & 0.086 & 0.072 & $*$ \\
\hline disabled persons & -0.163 & 0.125 & 0.192 & \\
\hline unemployment rate & -1.106 & 0.315 & 0.000 & $* * *$ \\
\hline constant & 0.224 & 0.613 & 0.715 & \\
\hline lambda & 4801.82 & 1873.51 & 0.010 & $* * *$ \\
\hline \multirow[t]{2}{*}{ rho } & 0.32 & & & \\
\hline & & Censored & Uncensored & \\
\hline Observation & 4236 & 1665 & 2571 & \\
\hline Wald chi2(14) & 1235.21 & & & \\
\hline Prob $>$ chi 2 & 0.00 & & & \\
\hline
\end{tabular}

Three, two and one starred $t$ values are significant at $99 \%, 95 \%$ and $90 \%$ respectively. Source: our elaboration of SHIW (2000) data. 
Table 9: Logit Model estimates.

\begin{tabular}{lcccc}
\hline Observations & 4236 \\
LR chi2 (14) & 1547,77 & & \\
Prob $>$ chi2 & 0,000 & & \\
Pseudo R2 & 0,2653 & & \\
Log-Likelihood & $-2143,56$ & & \\
Correctly classified & $74,48 \%$ \\
\hline \multicolumn{5}{c}{ Participation Equation } \\
\hline Covariates & Coef. & Std. Err. & signific. \\
\hline age & 0,165 & 0,069 & $* *$ & 0,039947 \\
age square & $-0,002$ & 0,001 & $* * *$ & $-0,000603$ \\
gender & 2,176 & 0,199 & $* * *$ & 0,411467 \\
north & $-0,024$ & 0,111 & & $-0,005871$ \\
south & $-0,780$ & 0,120 & $* * *$ & $-0,189550$ \\
schooling & 0,111 & 0,027 & $* * *$ & 0,026855 \\
children 0-5 & $-0,374$ & 0,116 & $* * *$ & $-0,091967$ \\
children 6-14 & $-0,314$ & 0,090 & $* * *$ & $-0,076573$ \\
elderly & 0,385 & 0,150 & $* * *$ & 0,089862 \\
disabled persons & $-0,019$ & 0,219 & & $-0,004595$ \\
unemployment rate & $-0,838$ & 0,498 & $*$ & $-0,202950$ \\
no labor income & $-0,000011$ & 0,000 & $* * *$ & $-0,000003$ \\
husband income & $-0,000007$ & 0,000 & $* * *$ & $-0,000002$ \\
own income & 0,000066 & 0,000 & $* * *$ & 0,000016 \\
constant & $-3,252$ & 1,477 & $* *$ & \\
\hline
\end{tabular}

Three, two and one starred t values are significant at $99 \%, 95 \%$ and $90 \%$ respectively. Source: our elaboration of SHIW (2000) data.

Table 10: Observed and predicted participation rates.

\begin{tabular}{lccc}
\hline & \multicolumn{3}{c}{ Household } \\
\cline { 2 - 4 } & all & disabled & no disabled \\
\cline { 2 - 4 } Predicted & 0.589 & 0.352 & 0.596 \\
Observed & 0.547 & 0.370 & 0.552 \\
\hline
\end{tabular}

Source: our elaboration of SHIW (2000) data.

Table 11: Elasticities.

\begin{tabular}{lccc}
\hline & \multicolumn{3}{c}{ Household } \\
\cline { 2 - 4 } Substitution & all & disabled & no disabled \\
\cline { 2 - 4 } Cross-substitution & 0.33 & 0.31 & 0.33 \\
Income & -0.08 & -0.10 & -0.08 \\
\hline
\end{tabular}

Source: our elaboration of SHIW (2000) data. 